\title{
PERFIL FERMENTATIVO E VALOR NUTRITIVO DE SILAGEM DE CAPIM-ELEFANTE INOCULADA COM STREPTOCOCCUS BOVIS
}

\author{
FERMENTATION AND NUTRITIVE VALUE OF ELEPHANT GRASS SILAGE INOCULATED \\ WITH STREPTOCOCCUS BOVIS
}

\author{
Ferreira, D.J. ${ }^{1 A}$, Zanine, A.M. ${ }^{2 A}$, Santos, E.M. ${ }^{3}$, Lana, R.P. ${ }^{1 B}$, Silva, W.L. ${ }^{4}$, Souza, A.L. ${ }^{2}$ \\ e Pereira, O.G. ${ }^{1}$
}

\begin{abstract}
${ }^{1}$ Universidade Federal de Viçosa/UFV.Viçosa, MG.Brasil. ${ }^{A} d a n y$ dosanjos@yahoo.com.br; Brlana@ufv.br 2Universidade Federal de Mato Grosso/UFMT. Rondonópolis, MT. Brasil. anderson. ${ }^{\mathrm{A} z a n i n e @ u f m t . b r}$ ${ }^{3}$ Universidade Federal da Paraíba/UFPB. Centro de Ciências Agrárias, Campus II. Areia, PB. Brasil. edsonzootecnista@yahoo.com.br

${ }^{4}$ Universidade Estadual Paulista - UNESP. Faculdade de Ciências Agrárias e Veterinária. Jaboticabal, SP. Brasil. wiltonladeira@yahoo.com.br
\end{abstract}

Palavras chave adicionais

Amônia. Fibra. Forragem. Proteína. pH.

\section{RESUMO}

O experimento foi desenvolvido objetivandose avaliar o efeito da inoculação de estirpes de Streptococcus bovis (HC5 e JB1) sobre o pH, a produção de amônia e o valor nutricional em silagens de capim-elefante (Pennisetum purpureum Schum). O delineamento experimental foi o inteiramente casualizado, com três tratamentos: T1 - capim-elefante, T2 - capimelefante inoculado com Streptococcus bovis $\mathrm{HC} 5$ e T3-capim-elefante inoculado com Streptococcus bovis JB1, utilizando cinco repetições por tratamento. A menor concentração de amônia foi observada na silagem tratada com inoculante à base Streptococcus bovis JB1 (5,90 p.100 Ntotal). A inoculação aumentou os teores de ácido láctico e diminuiu os teores de ácidos acético, butírico e propiônico, sendo que as silagens inoculada com Streptococcus bovis JB1 e HC5 foram os que apresentaram os maiores valores de ácido láctico. Não houve diferença estatística para os teores de MS e PB. Para os valores das fibras, a silagem de capim-elefante inoculada com Streptococcus bovis JB1 apresentou o menor valor de FDN (59,77 p.100) e HEM (26,71 p.100). O maior valor da DIVMS foi observado na silagem com Streptococcus bovis JB1, mostrando superioridade de quatro pontos percentuais $(64,23$ p.100) em relação ao tratamento sem inoculante

\author{
AdDITIONAL KEYWORDS \\ Ammonia. Forage. Fiber. Protein. pH.
}

bacteriano (60,35 p.100). O uso Streptococcus bovis JB1 melhora o processo fermentativo além de promover melhorarias na qualidade da fibra e na DIVMS da silagem estudada.

\section{SUMMARY}

The experiment was developed to evaluate the effect of strains of Streptococcus bovis (HC5 and JB1) on $\mathrm{pH}$, ammonia production and nutritional value in elephant-grass silages (Pennisetum purpureum Schum). The experimental design was entirely randomized, with three treatments: T1 elephant- grass, T2 - grass-elephant inoculated with Streptococcus bovis HC5, T3 - elephant grass inoculated with Streptococcus bovis JB1, totaling five replicates per treatment. The smallest value of ammonia was observed in the silage treated with inoculante the base Streptococcus bovis JB1 (5.90\% N-total). Inoculation increased the levels of lactic acid and decreased levels of acetic, propionic and butyric acids, and the silages inoculated with Streptococcus bovis JB1 and HC5 were those with the highest values of lactic acid. There were not statistical differences for the tenors of dry matter (MS) and crude protein (PB). For the values of the fibers, the grass-elephant silage inoculated with Streptococcus bovis JB1, 
it presented the smallest value of neutral detergent fiber (59.77\%) and Hemicellulose (26.71\%). The largest value of in vitro dry matter digestibility (DIVMS) was observed in the silage with Streptococcus bovis JB1, showing superiority of four percentile points $(64.23 \%)$ in relation to the treatment without bacterial inoculante (60.35\%). The use Streptococcus bovis JB1 was efficient in the process fermentativo besides promoting would get better in the quality of the fiber and DIVMS in the studied silage.

\section{INTRODUÇÃO}

O capim elefante (Pennisetum purpureum, Schum) é uma das mais importantes forrageiras tropicais devido ao seu elevado potencial de produção de biomassa, fácil adaptação aos diversos ecossistemas e boa aceitação pelos animais, sendo largamente utilizado na alimentação de rebanhos sob as formas de pastejo, feno e silagem.

Para que uma forrageira seja conservada sob a forma de silagem é necessário o predomínio da fermentação láctica sob condições de anaerobiose. Vários são os fatores que podem interferir na qualidade da fermentação. Entre eles citam-se a presença de bactérias homo e heterofermentativas, o teor de carboidratos solúveis, os teores de umidade e de matéria seca, a compactação e a rapidez no fechamento do silo (Patrizi et al., 2004).

A inoculação microbiana tem sido apontada como alternativa para melhorar o perfil fermentativo e o valor nutricional de silagens de algumas plantas forrageiras, embora os resultados encontrados sejam bastante variáveis (Bolsen et al., 1992). A maioria dos aditivos inoculantes contém cepas de bactérias lácticas homofermentativas, cuja finalidade é estimular rapidamente a fermentação láctica, reduzir o pH e inibir a ação das bactérias indesejáveis, principalmente as proteolíticas (Filya et al., 2000).

O Streptococcus bovis é uma bactéria láctica isolada do rúmen, com características que a possibilitam sua utilização como inoculante na ensilagem. A principal característica diz respeito à velocidade específica de crescimento desta espécie, $30 \%$ superior a outras espécies de bactérias lácticas utilizadas como inoculante para silagem, o que sugere que a mesma pode atuar como cultura start no processo fermentativo, promovendo uma rápida queda do $\mathrm{pH}$ do material ensilado (Jones et al., 1991). A aceleração da queda do $\mathrm{pH}$ favorece o crescimento das bactérias lácticas, em detrimento das enterobactérias, condição necessária para que o processo fermentativo ocorra de forma adequada.

Algumas linhagens de Streptococcus bovis, também, produzem bacteriocinas, que podem inibir o crescimento de microrganismos patógenos (Mantovani et al., 2002). Estes autores verificaram que uma estirpe de Streptococcus bovis, denominada HC5, produz uma bacteriocina (bovicina HC5) que inibe uma ampla variedade de microrganismos, incluindo bactérias do gênero Clostridium, indesejáveis no processo de silagem por serem proteolíticos e produzirem amônia. De forma similar, trabalhos preliminares de Streptococcus bovis, denominado JB1, mostraram-se resultados satisfatórios no perfil fermentativo e no valor nutritivo de silagem de capim-monbaça (Oliveira et al., 2007).

Desta forma, espera-se que a inoculação com Streptococcus bovis reduza a concentração de amônia na silagem, melhorando o seu valor nutritivo.

Com base no exposto, objetivou-se avaliar os efeitos da inoculação de duas estirpes de Streptococcus bovis (HC5 e JB1) sobre o $\mathrm{pH}$, a produção de amônia e o valor nutritivo da silagem de capim-elefante.

\section{MATERIAL EMÉTODOS}

O experimento foi realizado na Universidade Federal de Viçosa, localizada no município de Viçosa, Minas Gerais, Brasil. A cidade de Viçosa está situada a $20^{\circ}$ e $45^{\prime}$ 'de latitude sul, $42^{\circ}$ e $51^{\prime}$ de longitude oeste e

Archivos de zootecnia vol. 60, núm. 232, p. 1224. 
$657 \mathrm{~m}$ de altitude, apresentando precipitação média anual de $1341 \mathrm{~mm}$, dos quais cerca de $90 \%$ ocorrem nos meses de outubro a março. Utilizou-se uma capineira já implantada de capim-elefante (Pennisetum purpureum, Schum). Após um corte de uniformização a $30 \mathrm{~cm}$, adubou-se a capineira com $50 \mathrm{~kg} / \mathrm{ha}$ de $\mathrm{N}_{\text {e }} \mathrm{K}_{2} \mathrm{O}$ na forma de uréia e cloreto de potássio e, 90 dias após, efetuou-se o corte para ensilagem. O delineamento experimental foi o inteiramente casualizado, com três tratamentos: T1 - capim-elefante, T2 - capimelefante inoculado com Streptococcus bovis HC5, T3 - capim-elefante inoculado com Streptococcus bovis JB1, com cinco repetições por tratamento.

Para a inoculação, as culturas de Streptococcus bovis (HC5 e JB1) foram ativadas no dia anterior a ensilagem, em meio MRS (De man, Rogosa and Sharpe) e, como a contagem em placa havia acusado valores de $10^{9}$ unidades formadoras de colônia (UFC) por ml de meio, $10 \mathrm{ml}$ deste meio foi diluído 100 vezes, obtendo-se uma concentração de $10^{7}$ UFC por ml. Os $100 \mathrm{ml}$ deste meio foram aplicados em $10 \mathrm{~kg}$ de forragem, obtendo-se, desta forma, uma concentração de $10^{5} \mathrm{UFC} / \mathrm{g}$ de forragem fresca.

O capim foi picado em picadeira estacionária, com tamanho de partícula entre 2 e $3 \mathrm{~cm}$. O inoculante foi aplicado ao capim e, em seguida, efetuou-se a homogeneização. Para a ensilagem utilizaram-se silos de PVC de $10 \mathrm{~cm}$ de diâmetro e $45 \mathrm{~cm}$ de altura. Para avaliação da composição químico-bromatológica das silagens, foram coletadas amostras do material fresco, antes da ensilagem, e após a abertura dos silos (40 dias após a ensilagem). Estas amostras foram submetidas à pré-secagem por 72 horas em estufa de ventilação forçada a $65^{\circ} \mathrm{C}$ e, em seguida, foram moídas em moinho tipo Willey. Foram determinados os teores de matéria seca (MS), proteína bruta (PB), fibra em detergente neutro (FDN), fibra em detergente ácido (FDA), hemicelulose
(HEM) e digestibilidade in vitro da matéria seca (DIVMS), segundo metodologia descrita por (Silva e Queiroz, 2002). A composição químico-bromatológica do capim antes de ser ensilado encontra-se na tabela I.

Para a análise de $\mathrm{pH}$, foram coletadas subamostras de aproximadamente $25 \mathrm{~g}$, às quais foram adicionados $100 \mathrm{ml}$ de água, e, após repouso por 2 horas, efetuou-se a leitura do $\mathrm{pH}$, utilizando-se um potenciômetro. Em outra subamostra de 25 g, foram adicionados $200 \mathrm{ml}$ de uma solução de $\mathrm{H}_{2} \mathrm{SO}_{4}(0,2 \mathrm{~N})$, permanecendo em repouso por 48 horas para, em seguida, efetuar-se a filtragem em papel de filtro Whatman 54. Este filtrado foi armazenado em geladeira para posterior determinação do $\mathrm{N}$-amoniacal (Bolsen et al., 1992). Para determinação dos ácidos orgânicos, aproximadamente $25 \mathrm{~g}$ de silagem fresca foram diluídas em $250 \mathrm{ml}$ de água destilada e homogeneizadas em liquidificador industrial durante um minuto. O extrato aquoso resultante foi filtrado em filtro de papel, e $100 \mathrm{ml}$ foram acidificados com $\mathrm{H}_{2} \mathrm{SO}_{4} 50 \%$ e, posteriormente, filtradas em papel de filtragem rápida (Kung Jr. e

Tabela I. Valores médios de matéria seca $(M S)$, proteína bruta $(P B)$, fibras em detergente neutro (FDN) e ácido (FDA) e hemicelulose (HEM) dos tratamentos de capim-elefante (T1), capim-elefante com Streptococcus bovis HC5 (T2) o com S. bovis JB1 (T3) antes de ensilar. (Average values of dry matter (DM), crude protein (CP), neutral (NDF) and acid (ADF) detergent fibers, hemicellulose (HEM) for treatments: elephant grass (T1), elephant grass with Streptococcus bovis HC5 (T2) or S. bovis JB1 (T3) before ensilage).

\begin{tabular}{lccccc}
\hline & MS $^{1}$ & PB $^{2}$ & FDN $^{2}$ & FDA $^{2}$ & HEM $^{2}$ \\
\hline T1 & 28,02 & 8,40 & 67,92 & 32,65 & 35,27 \\
T2 & 28,67 & 7,99 & 65,56 & 33,12 & 32,44 \\
T3 & 27,34 & 8,16 & 66,77 & 34,23 & 32,54
\end{tabular}

${ }^{1}$ p. $100 ;{ }^{2}$ p.100 MS. 
Ranjit, 2001). Em 2 ml deste filtrado foram adicionados $1 \mathrm{ml}$ de solução de ácido metafosfórico $20 \%$ e $0,2 \mathrm{ml}$ de solução de ácido fênico 1\%, utilizado como padrão interno. A determinação dos ácidos láctico, acético, butírico e propiônico foi realizada por cromatografia líquida de alto desempenho (HPLC), marca Schimadzu SPD-10, com comprimento de onda de $210 \mathrm{~nm}$. Usouse uma coluna C-18, de fase reversa, com pressão de $168 \mathrm{kgf}$ e fluxo de $1,5 \mathrm{ml} /$ minuto. Os dados foram submetidos à análise de variância e os valores médios das variáveis avaliadas foram testados pelo teste de Tukey $(\alpha=0,05)$, utilizando-se o programa SAEG versão 8.1(SAEG, 1999).

\section{RESULTADOSEDISCUSSÃO}

Na tabela II encontram-se os valores médios de $\mathrm{pH}, \mathrm{N}-\mathrm{NH}_{3}$ e os ácidos graxos voláteis das silagens de capim-elefante, com e sem inoculação de Streptococcus bovis. Não se observou diferença estatística $(\mathrm{p}>0,05)$ entre o tratamento controle e os tratamentos inoculados para o valor de $\mathrm{pH}$, sendo que os valores de pHs obtidos para a obtenção de uma silagem de boa qualidade encontram-se na faixa ideal $(3,8$ a 4,2) (McDonald et al., 1991). Oliveira et al.(2007) avaliando a silagem de capim-mombaça tratada com inoculante a base de Streptococcus bovis HC5 e Streptococcus bovis JB1, 30 dias após a ensilagem, relataram valores de pH de 4,27 e 4,28 \%, respectivamente. Os autores observaram uma redução de dois pontos percentuais das silagens inoculadas com Streptococcus bovis em relação à testemunha. No presente experimento não foi observada redução no valor do $\mathrm{pH}$, como no experimento citado, provavelmente, devido à idade da planta (90 dias), tendo em vista que nesta idade, os capins apresentam elevadas populações microbianas, que promove maior produção de ácido.

Foi observado efeito $(p<0,05)$ dos inoculantes microbianos sobre os teores de amônia. Os menores valores $(\mathrm{p}<0,05)$ foram observados na silagem tratada com inoculante a base de Streptococcus bovis HC5 e Streptococcus bovis JB1, sendo o ultimo com menor valor (5,90\% $\mathrm{N}$-total), representando redução de aproximadamente, dois pontos percentuais em relação à silagem sem inoculante. Os menores valores obtidos para as silagens inoculadas foram, provavelmente, devido ao consumo de amônia, características da espécie Streptococcus bovis, como descrito por Mantovani et al. (2002), ou pela inibição de microrganismos proteolíticos. Oliveira et al. (2007) observaram que em silagens de capimmombaça, com aberturas de 1, 14 e 28 dias, que os tratamentos inoculados apresentaram menores concentrações de amônia, sendo o menor valor oriundo da silagem inoculada com Streptococcus bovis JB1, assim concordando com os resultados obtidos no presente experimento.

A inoculação na silagem de capim-elefante aumentou os teores de ácido láctico e diminuiu os teores de ácidos acético, butírico e propiônico (tabela II), sendo que as silagens inoculada com Streptococcus bovis JB1 e HC5 foram os que apresentaram os

Tabela II. Valores médios do N-amôniacal, pH e ácidos lático, acético, butírico e propiônico dos tratamentos de capim-elefante (T1), capim-elefante com 5 HC5 (T2) e com 5 JB1 (T3). (Average values of $\mathrm{NH}_{3}, \mathrm{pH}$ e lactic, acetic, propionic and butyric acids of treatments: elephant grass (T1), elephant grass with S. bovis HC5 (T2) or S. JB1 (T3)).

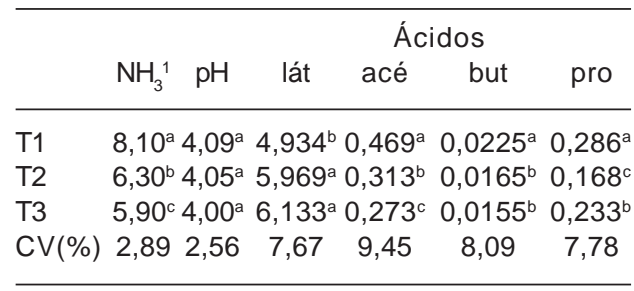

${ }^{1}$ p.100 N-total; Ácidos, p.100 MS; lat: lático; acé: acético; but: butírico; pro: propiônico. $p<0,05$ pelo teste Tukey. 
maiores valores $(\mathrm{p}<0,05)$ de ácido láctico, 6,133 e 5,969\% MS, respectivamente. Menores valores $(\mathrm{p}<0,05)$ de ácidos acético, butírico e propiônico também foram observados nessas silagens. De acordo com Santos et al. (2008), a maior produção de ácido láctico pode levar a menores perdas de MS em silagens, considerando-se que a fermentação láctica resulta em mínimas perdas, ao passo que as fermentações acética e butírica estão associadas a fermentações secundárias e perdas de MS na forma de gases.

Os valores de MS, PB, FDN, FDA, HEM e DIVMS, podem ser observados na tabela III. Não foram observadas diferenças estatísticas $(p>0,05)$ para os teores de MS e PB. Resultados semelhantes foram relatados por Rodrigues et al. (2001), que avaliaram o efeito do inoculantes (Streptococcus faecium e Lactobacillus plantarum) na silagem de capim elefante. Cheng et al. (2001) encontraram aumento significativo da PB de silagens de capim-elefante, com o uso de aditivo enzimo-bacteriano, enquanto que Clavero (2001) não obtiveram o mesmo efeito sobre a PB com o uso de dois aditivos biológicos, em cultivares de milheto e em capim-elefante $c v$ Mott, ao usarem bactérias lácticas.

Foi observada diferença estatística $(p<0,05)$ para os valores de FDN e HEM, em que a silagem de capim-elefante inoculada com Streptococcus bovis JB1, apresentou o menor valor de FDN (59,77\%) e HEM (26,71\%), provavelmente devido à hidrólise da hemicelulose pelo processo de fermentação realizada pela enzima dessa bactéria láctica, demonstrando eficiência do inoculo na melhoria do valor nutritivo da silagem. A silagem inoculada com o Streptococcus bovis HC5 não diferiu ( $\mathrm{p}>0,05)$ do tratamento controle.

Schaefer et al. (1989) trabalhando com inoculante bacteriano composto de Pediococcus acidilactici e Lactobacillus xylosus na forragem, relataram que houve redução na concentração de FDN e FDA na silagem de milho. Outros autores trabalhando com microrganismos produtores de ácidos lácticos potencializando a produção de silagem de capim, também verificaram efeitos positivos na qualidade da fibra (Zanine et al., 2007; Santos et al., 2008).

O maior valor da DIVMS foi observado para a silagem com Streptococcus bovis JB1, mostrando superioridade de quatro pontos percentuais $(64,23 \%)$ em relação ao tratamento sem inoculante bacteriano (60,35\%). O que pode ser devido à maior hidrólise observado nesse tratamento para a HEM $(29,71 \%)$, pois, de acordo com McDonald (1991) a hidrolise da HEM promove abertura na parede celular permitindo um maior ataque microbiano e, por conseqüência, aumenta-se a digestibilidade. Além do menor teor de FDN, implicando em maior digestibilidade. Não houve diferença estatística $(p>0,05)$ para a silagem testemunha e a tratada com inoculante contendo Streptococcus bovis HC5.

Tabela III. Valores médios de matéria seca (MS), proteína bruta (PB), fibra em detergente neutro (FDN), fibra em detergente ácido (FDA), hemicelulose (HEM) e digestibilidade in vitro da matéria seca (DIVMS) dos tratamentos de capim-elefante (T1), capim-elefante com Streptococcus bovis HC5 (T2) o com S. bovis JB1 (T3). (Average values of dry matter (DM), crude protein (CP), neutral detergent fiber (NDF), acid detergent fiber (ADF), hemicellulose (HEM) and in vitro digestibility of dry matter (IVDMD) of treatments: elephant grass (T1), elephant grass with Streptococcus bovis HC5 (T2) or S. bovis JB1 (T3)).

\begin{tabular}{lcccccc}
\hline & MS $^{1}$ & PB $^{2}$ & FDN $^{2}$ & FDA $^{2}$ & HEM $^{2}$ & DIVMS $^{2}$ \\
T1 & $31,14^{\mathrm{a}}$ & $6,50^{\mathrm{a}}$ & $63,6^{\mathrm{a}}$ & $29,90^{\mathrm{a}}$ & $33,75^{\mathrm{a}}$ & $60,35^{\mathrm{b}}$ \\
T2 & $30,24^{\mathrm{a}}$ & $6,50^{\mathrm{a}}$ & $64,3^{\mathrm{a}}$ & $29,52^{\mathrm{a}}$ & $34,86^{\mathrm{a}}$ & $60,69^{\mathrm{b}}$ \\
T3 & $30,90^{\mathrm{a}}$ & $6,52^{\mathrm{a}}$ & $59,7^{\mathrm{b}}$ & $30,06^{\mathrm{a}}$ & $29,71^{\mathrm{b}}$ & $64,63^{\mathrm{a}}$ \\
CV(\%) & 5,03 & 1,24 & 7,65 & 1,84 & 1,66 & 3,48 \\
\hline
\end{tabular}

${ }^{1}$ p.100; ${ }^{2}$ p.100 MS. $p<0,05$ pelo teste Tukey. 
Efeitos positivos do uso de inoculantes sobre a DIVMS foram relatados por Mayne (1990), Martinsson (1992) e Santos et al. (2008) os quais observaram melhora na digestibilidade dos nutrientes com a inoculação microbiana da silagem de capim.

\section{BIBLIOGRAFIA}

Bolsen, K.K., Lin, C., Brent, B.E. and Gadeken, D. 1992. Effect of silage additives on the microbial succession and fermentation process of alfalfa and corn silages. J. Dairy Sci., 75: 3066-3083.

Cheng, Y.K., Chen, C.S. and Peng, P.W. 2001. Effects of different additives on silage quality of napiergrass. In: Proceedings... International Grassland Congress, 19: 771-772.

Clavero, T. 2001. Quality and nutritive value of Mott dwarf elephantgrass silage with biological additives. In: Proceedings... International Grassland Congress, 19: 770-771.

Filya, I., Ashbell, G. and Hen, Y. 2000. The effect of bacterial inoculants on the fermentation and aerobic stability of whole crop wheat silage. Anim. Feed Sci. Techn., 88: 39-46.

Kung Jr., L. and Ranjit, N.K. 2001. The effect of Lactobacillus buchneri and other additives on the fermentation and aerobic stability of barley silage. J. Dairy Sci., 84: 1149-1155.

Jones, B.A., Muck, R.E. and Rick, S.C. 1991. Selection and application of Streptococcus bovis as a silage inoculant. Appl. Env. Microb., 57: 3000-3005.

Mantovani, H.C., Worobo, R.W. and Russel, J.B. 2002. Bovicin HC5, a bacteriocin from Streptococcus bovis HC5. Microbiology, 148: 3347-3352.

Martinsson, K.A. 1992. Study of the efficacy of a bacterial inoculant and formic acid as additive for grass silage in terms of milk production. Grass. For. Sci., 47: 189-198.

Mayne, C.S. 1990. An evaluation of an inoculant of Lactobacillus plantarum as an additive for grass silage for dairy cattle. Anim. Prod., 51: 1-13.

McDonald, P., Henderson, A.R. and Heron, S. 1991. The biochemist of silage. $2^{\mathrm{a}}$ ed. Chalcombe Publications. Marlow. 340 pp.

Oliveira, J.S., Santos, E.M., Zanine, A.M., Mantovani, H.C., Pereira, O.G. e Rosa, L.O.

\section{CONCLUSÕES}

O uso de $S$. bovis JB1 diminui a concentração de amônia e de ácidos graxos indesejáveis, melhorando a fermentação, além de reduzir o teor de FDN e aumentar a digestibilidade da silagem de capim-elefante.

2007. Populações microbianas e composição química de silagem de capim mombaça (Panicum maximum) inoculado com Streptococcus bovis isolado de rúmen. Arch. Veter. Sci., 12: 35-40. Patrizi, C.R.F., Madruga Júnior, T.P., Minetto, E. e Nogueira, M.G. 2004. Efeito de aditivos biológicos comerciais na silagem de capim-elefante (Pennisetum purpureum Schum). Arq. Bras. Med. Veter. Zoot., 56: 392-397.

Rodrigues, P.H.M., Almeida, T.F. and Melotti, L. 2001. Efeitos da adição de inoculantes microbianos sobre a composição bromatológica e sobre a fermentação da silagem de girassol produzida em silos experimentais. Rev. Soc. Bras. Zootecn., 30: 2169-2175.

Santos, E.M., Zanine, A.M., Ferreira, D.J., Oliveira, J.S., Penteado, D.C.S. and Pereira, O.G. 2008. Inoculante ativado melhora a silagem de capimtanzânia (Panicum maximum). Arch. Zoot., 215: 1-8.

Schaefer, D.M., Brotz, P.G., Arp, S.C. and Cook, D.K. 1989. Inoculation of corn silage and highmoisture corn with lactic acid bacteria and its effect on the subsequent fermentation and on feedlot performance of beef steers. Anim. Feed Sci. Techn., 25: 23-38.

Silva, D.J. and Queiroz, A.C. 2002. Análise de alimentos: métodos químicos e biológicos. $3^{\mathrm{a}} \mathrm{ed}$. Impr. Universitária. Viçosa. 235 pp.

SAEG. Sistema de análises estatísticas e genéticas. 1999. Manual do usuário. (versão 8.0). Ed. Universidade Federal de Viçosa. Viçosa. 138 pp.

Zanine, A.M., Santos, E.M., Ferreira, D.J., Pinto, L.F.B. e Pereira, O.G. 2007. Características fermentativas e composição químico-bromatológica de silagens de capim-elefante com ou sem Lactobacillus plantarum e farelo de trigo isoladamente ou em combinação. Cien. Anim. Bras., 8: 621-628. 